\title{
Numerical Thermo-Mechanical Stress Analysis for HVDC Cables
}

\author{
Z. Y. Huang*, J. A. Pilgrim, P. L. Lewin and S. G. \\ Swingler \\ Tony Davies High Voltage Laboratory \\ University of Southampton \\ Southampton, United Kingdom \\ *zh2g09@soton.ac.uk
}

\author{
G. Tzemis \\ Electricity Transmission Asset Management \\ National Grid \\ Warwick, United Kingdom
}

\begin{abstract}
Calculating the current rating of paper insulated HVDC cables under low ambient temperatures can require additional mechanical considerations. Under rapid cable heating or cooling processes, an extremely high mechanical stress or a rapid pressure drop can develop due to the strong impregnant thermal expansion or contraction respectively. This may cause plastic deformation of the sheath or the creation of voids. This paper demonstrates the importance of this thermo-mechanical constraint through the application of finite element modelling techniques which permit a coupling of the thermal and mechanical properties within the cable. The results show that the FEA technique can be fully applied to analyze the internal thermo-mechanical stress distribution of the cable and calculate the resulting mechanical stress-limited rating, which provides an alternative to an analytical method previously developed by the same author.
\end{abstract}

Keywords - finite element analysis; HVDC transmission; thermal expansion; underwater cables

\section{INTRODUCTION}

At present, high voltage dc (HVDC) cable links are becoming an increasingly important component of transmission grids, particularly in the form of interconnectors. Although cross-linked polyethylene (XLPE) is the prevalent dielectric for links with lower capacity, HVDC cable systems which operate at above $350 \mathrm{kV}$ are still primarily constructed using mass impregnated (MI) paper technology. Unlike may transmission cable circuits, market-driven interconnectors frequently operate at full rated current, meaning that the accuracy of the current rating calculation becomes critical to the long term health of cable asset.

The main challenge posed by HVDC MI cable systems is that, unlike most ac cable systems, the current rating is not just restricted by the thermal limit of the dielectric, normally outlined by the IEC60287 [1]. In addition, for some high power HVDC cables with MI paper insulation, extra restrictions are imposed on the cable operation, under low ambient temperatures. It is believed that unacceptably high interfacial mechanical stress transients, due to the strong thermal expansion of the high viscosity impregnant, can occur under rapid loading increases. Moreover, big pressure drops can also occur during cable cooling, which might reduce the dielectric strength by introducing voids. Therefore it is important to investigate this thermo-mechanical phenomenon. As the dielectric thermal expansion is closely linked to the cable current rating through the conductor joule loss, it is also of great value if the thermo-mechanical stress limited rating can be identified. Although a review of the literature suggests that an analytical calculation has been proposed based on the idea of pressure vessel [2], a large number of equations need to be solved.

This paper uses the Finite Element Analysis (FEA) technique as an alternative to model the interactions between the thermal and mechanical stress fields, allowing a thermomechanical rather than simply thermal rating criterion to be applied. The model presented here can be set up in around 30 mins, with each numerical analysis taking less than 2 mins on a standard dual-core laptop. Moreover, the results demonstrate the importance of correctly considering the mechanical stress, with a number of scenarios identified where it can become the limiting factor on the power transfer capability of the cable circuit. Combined with other work by the same author [3], this allows the rating of the cable to be systematically considered for the three limiting factors of temperature, electric stress and mechanical stress.

\section{Multi-Physics}

This chapter firstly explains in detail the fundamental physics behind the problem and the modelling assumptions. Secondly, the governing partial differential equations (PDEs) are summarized, which demonstrates the applicability of FEA modelling from a theoretical perspective.

\section{A. Problem Fundamentals \& Modelling assumptions}

To determine the cable internal mechanical stress distribution as a function of cable load current, a multi-physics combination of elasticity theory, thermodynamics and electrical fundamentals is required. Table I below summarizes the necessary knowledge input from each of the above three physical theories, and Fig. 1 outlines the multi-physics interaction towards a thermo-mechanical stress limited rating mechanism.

\footnotetext{
The financial support of National Grid plc is gratefully acknowledged
} 
TABLE I. SUMMARY OF CONCEPTUAL INPUT

\begin{tabular}{|c|c|}
\hline Physics & \multicolumn{1}{c|}{ Knowledge } \\
\hline $\begin{array}{c}\text { Theory of } \\
\text { elasticity }\end{array}$ & $\bullet \begin{array}{l}\text { Plain stress/ strain analysis for } \\
\text { cylindrical coordinates } \\
\text { Mechanical failure criterion and its } \\
\text { location }\end{array}$ \\
\hline Thermodynamics & • $\begin{array}{l}\text { Linear/ volumetric thermal expansion } \\
\text { Conductive heat transfer mechanism }\end{array}$ \\
\hline $\begin{array}{c}\text { Electrical } \\
\text { fundamentals }\end{array}$ & - Ohmic loss calculation \\
\hline
\end{tabular}

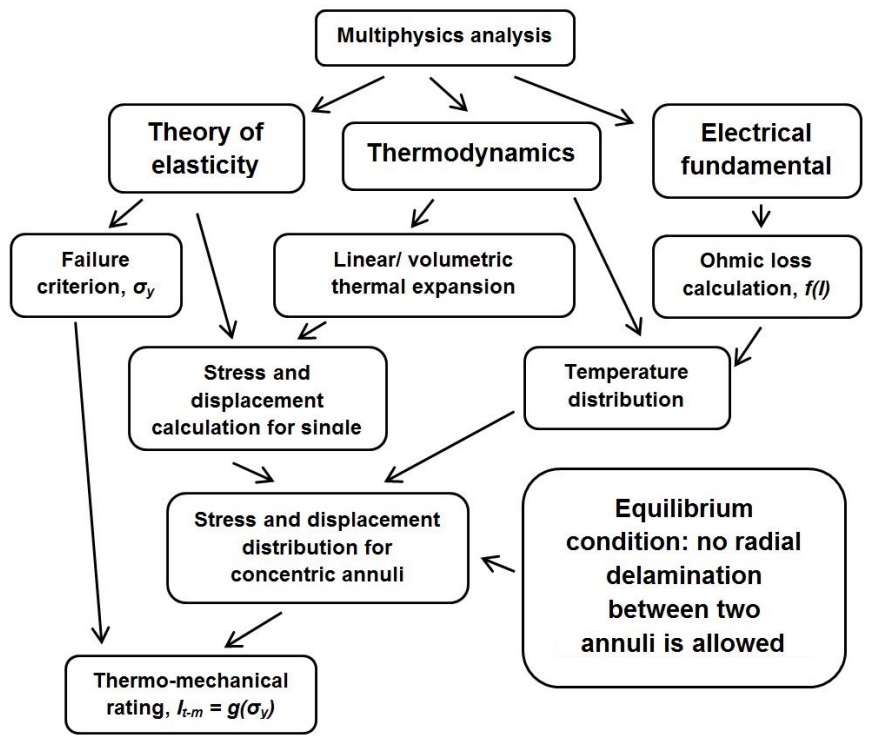

Fig. 1. Multi-physics Interaction

Note that the logic in Fig. 1 has also been demonstrated in [2], which helps to derive an analytical calculation.

Overall, the most challenging part of the FEA modelling is to accurately present the mass impregnated paper insulation layer, which is a mixture of Kraft paper and high viscosity impregnant (mineral oil T2015). Therefore, it doesn't solely belong to either of the solid or liquid state. Although previous work tried to calculate the actual fluid dynamics under the thermal stress [4], it is time consuming (involves numerical programming) and challenging for less experienced users without a strong mathematical backgroud. Therefore, two extreme situations are firstly considered in this work. At 'low temperature', the insulation is assumed to be isotropic and elastic with equivalent thermal and mechanical proporties because the impregnant viscosity remains high. However at 'high temperature', the insulation is assumed to have 'rigid' paper and incompressible liquid [5]. In addition, only the liquid component contributes to the overall thermal expansion. This assumption depends on the fact that the impregnant oil has a much higher thermal expansion coefficient than Kraft paper $\left(\alpha_{v \text {-impregnant }} \approx 7 \times 10^{-4} \mathrm{~K}^{-1}, \alpha_{v \text {-paper }} \approx 4 \times 10^{-5} \mathrm{~K}^{-1}[6]\right)$ and its viscosity decreases with increasing temperature. In addition, only the thermal conduction mechanism is considered for the above two extremes, while the liquid convection effect is ignored due to the low permeability of the Kraft paper.

\section{B. Governing Equation}

Within the theory of elasticity, plane stress and plane strain are two distinct simplified models for 2D plane analyses [7]. The plane stress is defined to be a stress state where the normal stress and associated shear stresses ( $\mathrm{z}$ direction) perpendicular to the $x-y$ plane, are assumed to be zero. This model applies to practical situations where objects have one dimension extremely small compared to the other two or extremely long cables without end constraints (free longitudinal expansion at cable ends).

The plane strain is defined to be another 2D stress state where the normal strain and associated shear strains ( $\mathrm{z}$ direction), directed perpendicular to the $x-y$ plane, are assumed to be zero. This model applies to practical situations where objects have one dimension extremely large compared with the other two, e.g. cables with constrained ends. However, both states are based the same PDE describing the local relationship onto an infinitesimal element, shown as below:

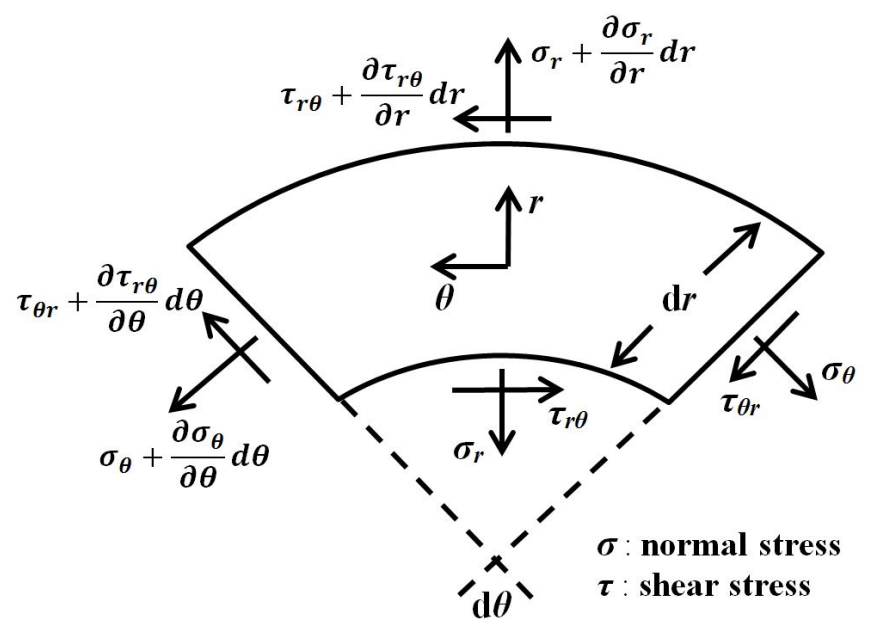

Fig. 2. local stress on an infinitesimal element

In Fig. 2, all the four shear stresses are balanced out due to the annular symmetry and the governing PDE, (1), is derived by equaling the stresses in both radial $(r)$ and circumferential $(\theta)$ directions [7].

$$
r \frac{d \sigma_{r}}{d r}+\left(\sigma_{r}-\sigma_{\theta}\right)=0
$$

Where; $r$ is radial coordinate $(\mathrm{m}), \sigma_{r}$ the radial stress $\left(\mathrm{N} \cdot \mathrm{m}^{-2}\right)$ and $\sigma_{\theta}$ is the circumferential stress $\left(\mathrm{N} . \mathrm{m}^{-2}\right)$. Note that both plane stress and strain modes are available in FEA modelling packages (e.g. COMSOL) and the plane stress is selected in this paper as a demonstration.

A well-recognized failure/ yield criterion applicable to cable sheath is Tresca's (maximum shear stress) criterion for ductile materials [8], such as aluminium and lead. Under this criterion, yield is caused by the slippage of crystal planes along the maximum shear stress surface. Therefore, it requires the maximum shear stress (principle stress difference) to be less 
than the material yield shear stress, which can be measured through a uniaxial tensile test.

$$
\left|\sigma_{r}-\sigma_{\theta}\right| \leq \sigma_{y}
$$

Where; $\sigma_{y}$ is the maximum yield shear stress $\left(\mathrm{N} \cdot \mathrm{m}^{-2}\right)$ and any value above it leads to a plastic deformation. From [2], the maximum shear stress normally locates near the inner surface of an annulus.

Within thermodynamics, most engineering materials are considered to be in either solid or liquid state, where thermal expansion is the tendency of matter to change in volume in response to a change in temperature [9].

$$
\begin{aligned}
& \Delta L=\alpha_{L} L \Delta T \\
& \Delta V=\alpha_{V} V \Delta T
\end{aligned}
$$

Where; $\Delta L$ and $\Delta V$ are the change in length (m) and volume $\left(\mathrm{m}^{3}\right), L$ and $V$ the original length $(\mathrm{m})$ and volume $\left(\mathrm{m}^{3}\right), \alpha_{L}$ and $\alpha_{V}$ are the linear and volumetric thermal expansion coefficients $\left(\mathrm{K}^{-1}\right)$, and $\Delta T$ is the temperature change $(\mathrm{K})$. Note that for isotropic materials, $\alpha_{V}=3 \alpha_{L}$.

In order to calculate the temperature distribution within the cable, the well-known heat transfer equation of thermal conduction is applied [9] as:

$$
\rho C_{p} \frac{\partial T}{\partial t}+\rho C_{p} u \cdot \Delta T=\nabla \cdot(k \nabla T)+Q
$$

Where; $\rho$ is the mass density $\left(\mathrm{kg} \cdot \mathrm{m}^{-3}\right), C_{p}$ the specific heat capacity $\left(\mathrm{J}^{\mathrm{kg}}{ }^{-1} \cdot \mathrm{K}^{-1}\right), T$ the absolute temperature $(\mathrm{K})$, u the velocity vector $\left(\mathrm{m} \cdot \mathrm{s}^{-1}\right), k$ the thermal conductivity $\left(\mathrm{W} \cdot \mathrm{m}^{-1} \cdot \mathrm{K}^{-1}\right)$, and $Q$ is heat source $\left(\mathrm{W} \cdot \mathrm{m}^{-3}\right)$. Note that under steady state or neglecting the thermal convection, the two terms on the left side of (5) equal to zero.

Within the electrical fundamentals, the conductor joule loss, $W_{c}$, is identified as the only heat source under a dc application, which is calculated by:

$$
W_{c}=\frac{\rho_{r e s} L}{A}\left[1+\alpha_{20}(T-293.15)\right]
$$

Where; $\rho_{\text {res }}$ is the cable conductor electrical resistivity $\left(\Omega \cdot \mathrm{m}^{-1}\right)$, $A$ the conductor cross section area $\left(\mathrm{m}^{2}\right)$, and $\alpha_{20}$ is the constant mass temperature coefficient at $20^{\circ} \mathrm{C}\left(\mathrm{K}^{-1}\right)$. Note that the dielectric leakage current loss is neglected compared to the much greater conductor joule loss $\left(W_{\text {joule }} \approx 20-30 \mathrm{~W} \cdot \mathrm{m}^{-1}\right.$, $\left.W_{\text {leakage }}<0.5 \mathrm{~W} \cdot \mathrm{m}^{-1}\right)$.

\section{CABle PARAMETER AND MODELling APPROACH}

This chapter comprehensively summarises the geometry, material properties, physical equations and boundary conditions specified in the proposed FEA model. It is believed that the whole process is fully replicable for most users.

\section{A. Model Parameters}

\begin{tabular}{|c|c|c|}
\hline Parameter & Value & Unit \\
\hline Conductor material & copper & - \\
\hline Conductor density & 8700 & kg. $\mathrm{m}^{-3}$ \\
\hline Conductor cross section & 2500 & $\mathrm{~mm}^{2}$ \\
\hline Conductor outer diameter & 60.5 & $\mathrm{~mm}$ \\
\hline Conductor Poisson's ratio & 0.35 & - \\
\hline Conductor Young's modulus & $1.1 \times 10^{11}$ & N.m ${ }^{-2}$ \\
\hline Conductor electric resistivity & $1.7241 \times 10^{-8}$ & $\Omega . \mathrm{m}$ \\
\hline Conductor thermal resistivity & 0.0026 & K.m.W $\mathrm{W}^{-1}$ \\
\hline $\begin{array}{c}\text { Conductor linear thermal } \\
\text { expansion coefficient }\end{array}$ & $1.7 \times 10^{-5}$ & $\mathrm{~K}^{-1}$ \\
\hline Insulation material & MI Kraft paper & - \\
\hline Kraft Paper porosity & $0.2-0.5$ & - \\
\hline Kraft paper density & 1000 & kg. $\mathrm{m}^{-3}$ \\
\hline Impregnant density & $939[4]$ & kg. $\mathrm{m}^{-3}$ \\
\hline Insulation outer diameter & 103 & $\mathrm{~mm}$ \\
\hline Insulation Poisson's ratio & 0.499 & - \\
\hline Insulation thermal resistivity & 6 & K.m.W. $\mathrm{W}^{-1}$ \\
\hline $\begin{array}{l}\text { Impregnant volumetric thermal } \\
\text { expansion coefficient }\end{array}$ & $7 \times 10^{-4}$ & $\mathrm{~K}^{-1}$ \\
\hline $\begin{array}{c}\text { Paper volumetric thermal } \\
\text { expansion coefficient }\end{array}$ & $0.4 \times 10^{-4}$ & $\mathrm{~K}^{-1}$ \\
\hline Sheath material & Aluminium & - \\
\hline Sheath density & 2700 & kg. $\mathrm{m}^{-3}$ \\
\hline Sheath outer diameter & 111 & $\mathrm{~mm}$ \\
\hline Sheath Poisson's ratio & 0.33 & - \\
\hline Sheath yield stress & $1.3 \times 10^{8}[10]$ & N.m ${ }^{-2}$ \\
\hline Sheath Young's modulus & $0.7 \times 10^{11}$ & N.m ${ }^{-2}$ \\
\hline Sheath thermal resistivity & 0.0042 & K.m.W $\mathrm{W}^{-1}$ \\
\hline $\begin{array}{l}\text { Sheath linear thermal expansion } \\
\text { coefficient }\end{array}$ & $2.3 \times 10^{-5}$ & $\mathrm{~K}^{-1}$ \\
\hline Serving material & $\mathrm{PE}$ & - \\
\hline Serving density & 920 & kg. $\mathrm{m}^{-3}$ \\
\hline Serving outer diameter & 120 & $\mathrm{~mm}$ \\
\hline Serving Poisson's ratio & 0.46 & - \\
\hline Serving Young's modulus & $0.004 \times 10^{11}$ & N.m ${ }^{-2}$ \\
\hline Serving thermal resistivity & 3.5 & K.m.W $\mathrm{W}^{-1}$ \\
\hline $\begin{array}{l}\text { Serving linear thermal expansion } \\
\text { coefficient }\end{array}$ & $12 \times 10^{-5}[12]$ & $\mathrm{K}^{-1}$ \\
\hline Backfill material & Fine sandy soil & - \\
\hline Backfill density & $1800[13]$ & kg. $\mathrm{m}^{-3}$ \\
\hline Backfill Poisson's ratio & $0.325[13]$ & - \\
\hline Backfill Young's modulus & $0.0005 \times 10^{11}[13]$ & N.m ${ }^{-2}$ \\
\hline Backfill thermal resistivity & $0.7[14]$ & K.m.W. $\mathrm{W}^{-1}$ \\
\hline $\begin{array}{c}\text { Backfill linear thermal expansion } \\
\text { coefficient }\end{array}$ & $0.05 \times 10^{-5}[15]$ & $\mathrm{K}^{-1}$ \\
\hline Submarine ambient temperature & 4 & ${ }^{\circ} \mathrm{C}$ \\
\hline
\end{tabular}

This work considers a mass impregnated, paper insulated submarine monopole cable, the parameters of which are shown in Table II.

TABLE II. CABle PARAMETERS

Note that normally in solid mechanics, the dielectric impregnant doesn't have a well-defined Poisson's ratio (ratio of transverse strain to axial strain) due to its liquid character. However, this parameter is arbitrarily designed in Table II to reflect the impressive impregnant under the 'high temperature' environment, based on the following equation [7]:

$$
B=\frac{E}{3(1-2 v)}
$$

Where; $B$ is the bulk modulus (reciprocal of compressibility), $E$ the Young's modulus and $v$ is the Poisson's ratio. In other words, the stagnant liquid is modelled as an incompressible 'solid' with high thermal expansion coefficient. This technique 
depends on both the low permeability of Kraft paper and the incompressible nature of the impregnant. Moreover, it helps to avoid a complex CFD modelling.

Under the 'low temperature' environment where the viscosity of impregnant remains high, the insulation is assumed to be isotropic and elastic with equivalent Poisson's ratio and Young's modulus. The main difficulty is to design experiments to measure these two parameters, which falls outside the scope of this paper. However, once these two parameters are quantified, they can be easily applied to the FEA model as inputs.

As the Kraft paper is a porous media filled with impregnant, the equivalent density, $\rho_{e q}$, and thermal expansion coefficient, $\alpha_{e q}$, of a unit insulation volume is calculated as a function of porosity, $\Phi$, shown in (8) and (9).

$$
\begin{aligned}
& \rho_{e q}(\phi)=\phi \rho_{\text {im }}+(1-\phi) \rho_{\text {paper }} \\
& \alpha_{\text {eq }}(\phi)=\phi \alpha_{i m}+(1-\phi) \alpha_{\text {paper }}
\end{aligned}
$$

Where; $\rho_{\text {im }}$ and $\rho_{\text {paper }}$ are the mass density of dielectric impregnant and Kraft paper $\left(\mathrm{kg} . \mathrm{m}^{-3}\right)$, and $\alpha_{i m}$ and $\alpha_{\text {paper }}$ are the thermal expansion coefficient of the dielectric impregnant and Kraft paper $\left(\mathrm{K}^{-1}\right)$.

The backfill volumetric heat capacity is calculated through an empirical formula (10), initially proposed by Neher [16].

$$
S=\frac{k_{\text {soil }}^{0.2}}{4.68 \rho_{\text {soil }}} 10^{7}
$$

Where; $k_{\text {soil }}$ is the soil thermal conductivity $\left(\mathrm{W} \cdot \mathrm{m}^{-1} \cdot \mathrm{K}^{-1}\right)$ and $\rho_{\text {soil }}$ is the soil mass density $\left(\mathrm{kg} \cdot \mathrm{m}^{-3}\right)$.

\section{B. Model Setting Up}

Correctly defining boundary conditions is critical to any FEA model. As the mechanical stress analysis involves two inter-linked physical interfaces: thermal and mechanical; boundary specification is explained in two categories together with the dominating mathematical equation respectively. The boundary location is illustrated in Fig. 3.

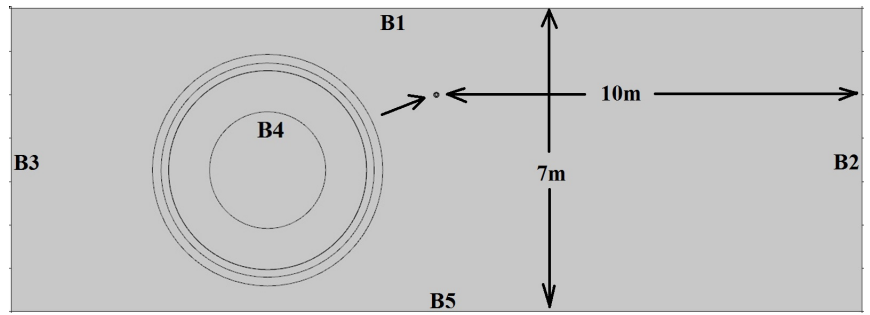

Fig. 3. Illustration of model geometry and boundry setting

Under the thermal interface, the ground boundary B1 is isothermal, with the side boundary B2 and B3 assumed to be thermal insulating. It assumes no heat flux crosses the boundary, by providing enough distance away from the cable center $(10 \mathrm{~m}$ is proved adequate in [17]). The governing equation is:

$$
-n \cdot(-k \nabla T)=0
$$

Where; $n$ is the unit vector normal to the surface and $k$ is the thermal conductivity $\left(\mathrm{W} \cdot \mathrm{m}^{-1} \cdot \mathrm{K}^{-1}\right)$. The conductor outer boundary B4 is defined as heat source by (6) and the bottom boundary B5 has a distributed temperature profile to account for the temperature rise caused by the cable above, which is defined by:

$$
T=T_{a m b}+\sum_{j=1}^{n} \frac{W_{t j}}{2 \pi k_{\text {soil }}} \ln \left(\frac{d_{j}^{\prime}}{d_{j}}\right)
$$

Where; $T_{a m b}$ is the ambient backfill temperature $\left({ }^{\circ} \mathrm{C}\right), W_{t j}$ is the total losses of cable $j\left(\mathrm{~W} . \mathrm{m}^{-1}\right), d_{j}$ is the distance from the point under consideration to the actual burial cable $k(\mathrm{~m})$ and $d_{j}{ }^{\prime}$ is the distance to the image of buried cable $k(\mathrm{~m})$. The applicability of (12) has been supported by comparison to the 'infinite elements domain', which adopts a coordinate scaling to a layer of virtual domains surrounding the physical region of interest. However, applying (12) avoids complex boundary settings in FEA. Refer to [3] for more details.

Under the mechanical interface, two boundary conditions are required simultaneously to solve (1) uniquely. Boundary load is defined on B1 representing the submarine hydraulic pressure (assume $1 \times 10^{6} \mathrm{~N} \cdot \mathrm{m}^{-2}$ at $100 \mathrm{~m}$ deep) and fixed constraints are defined on B1, B2, B3 and B5 to limit any physical displacement.

\section{SOLUTION PROCEDURE \& DisCUSSION}

This chapter presents the simulation results together with detailed discussion under steady state. The cable is buried $2 \mathrm{~m}$ below the seabed to achieve a minimum burial protection index of 1 [18] and the paper porosity is varying from 0.2 to 0.5 . Figure 4 below firstly show the thermal field distribution.

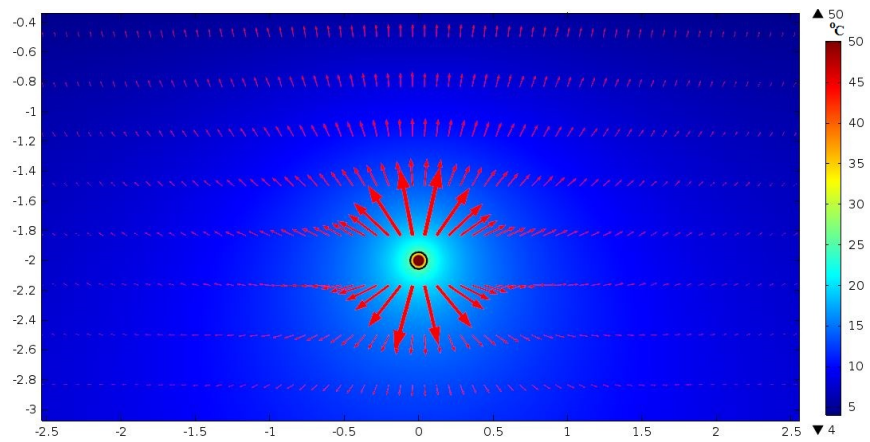

Fig. 4. Thermal field distribution and totale heat flux

Figure 4 shows the temperature distribution and the red arrows represent the total heat flux. It can be seen that the maximum temperature is $50^{\circ} \mathrm{C}$ under a rating of $2415 \mathrm{~A}$ and the horizontal heat flux is almost negligible at $2.5 \mathrm{~m}$ away from the cable centre, which verifies the $10 \mathrm{~m}$ setting in Fig. 3. In Fig. 5 and Fig.6 below, the Tresca stress distribution is ploted under the same current loading. 


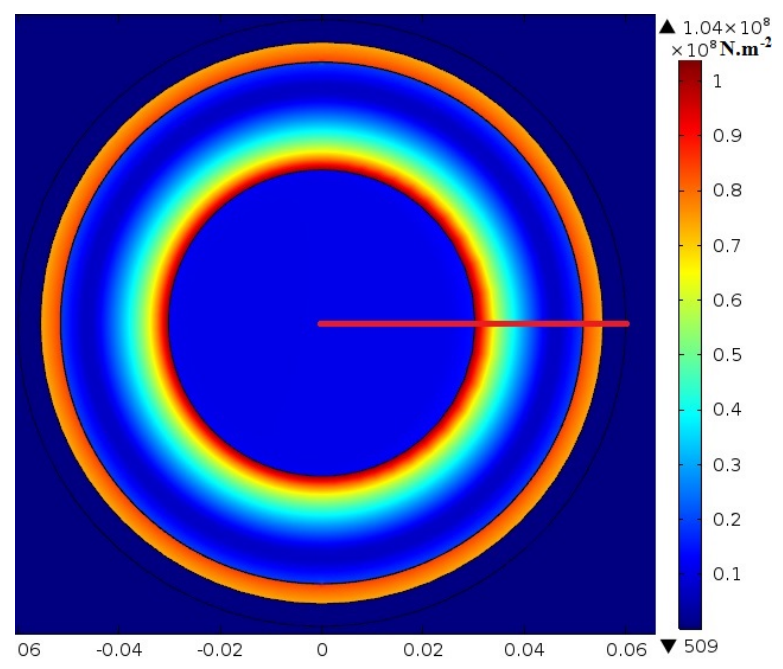

Fig. 5. Tresca stress field distribution

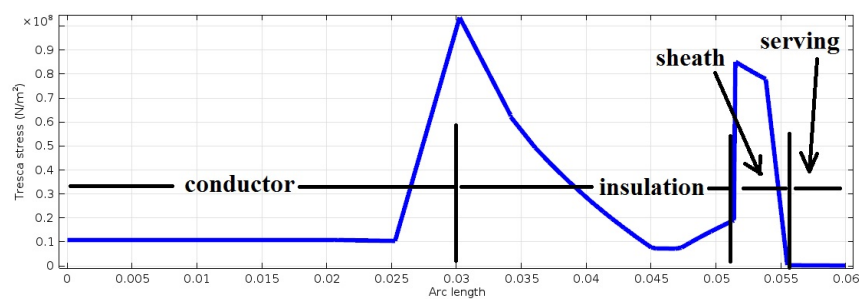

Fig. 6. Tresca stress plot along the radial line (red in Fig. 5)

Figure 6 plots the Tresca stress along the red line defined in Fig. 5. It shows three clear discontinuities at boundaries between conductor, insulation, sheath and serving due to a change of material. In addition, it verifies that the maximum Tresca stress of the sheath is located close to its inner boundary. Although the global maximum value is at the conductor outer boundary, it is always compressive and won't lead to any voids. Fig. 7 below plots the maximum sheath Tresca stress against various paper porosities and current loadings.

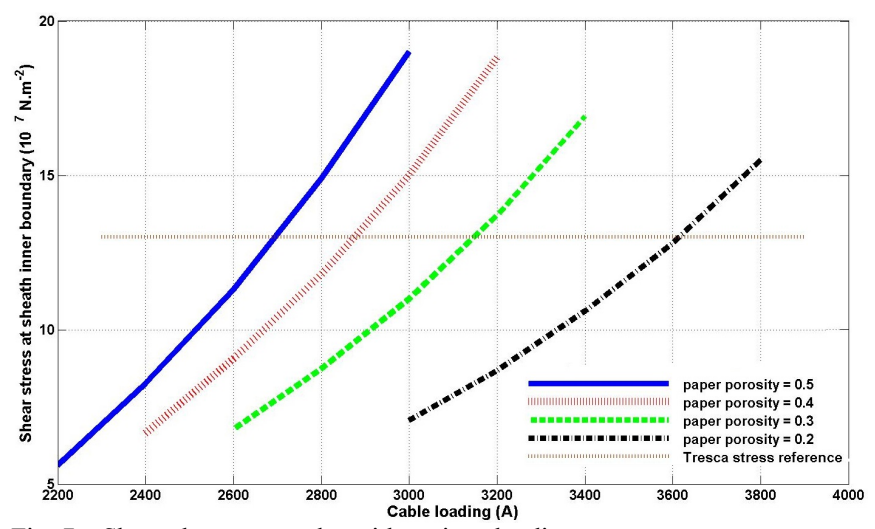

Fig. 7. Shear shear stress plot with various loadings

In Fig. 7, the thermo-mechanical rating (intersection with reference line) ranges from $2600 \mathrm{~A}$ to $3700 \mathrm{~A}$, and it increases with decreasing paper porosity. This is expected as the total volume of impregnant present in the cable has decreased, hence reducing the extent of the dielectric thermal expansion.

\section{CONCLUSIONS}

This paper has presented and demonstrated a numerical method to analyze the thermo-mechanical stress distribution within HVDC MI-type submarine cables operating, through the application of FEA modelling. Further the concept of thermo-mechanical rating is introduced, calculating the cable rating as a function of maximum sheath Tresca stress. As an initial approach, this work analyzes the effect of applying a steady current to the cable under the worst case scenario. Further work is required to solve the model in transient state by adding thermal capacities and examine the mechanical stress field under various loading modes.

\section{REFERENCES}

[1] Electric cables - Calculation of the current rating - Current rating equation ( $100 \%$ load factor) and calculation of losses - General, BS IEC 60287-1-1, 2006 .

[2] Z. Y. Huang and J. A. Pilgrim, "Thermo-mechanical pressure analysis for HVDC cables," in Jicable HVDC'13, P14, Perpignan, 2013.

[3] Z. Y. Huang, J. A. Pilgrim, P. L. Lewin, S. G. Swingler and D. Payne, "Current rating methodology for mass impregnated HVDC cables," in IEEE Electrical Insulation Conference, pp. 513-517, Ottawa, 2013.

[4] P. Szabo, O. Hassager and E. Strobech, "Modeling of pressure effects in HVDC cables," in IEEE Transactions on Dielectrics and Electrical Insulation, vol. 6, pp. 845-851, 1999.

[5] P. P. Benham, R. J. Crawford and C. G. Amstrong, Mechanics of Engineering Materials [second edition], Harlow: Pearson/ Prentice Hall, 1996.

[6] J. Borch, M. B. Lyne, R. E. Mark and C. C. Habeger, Handbook of Physical Testing of Paper: Volume 2, United State: CRC Press, 2001.

[7] S. Timoshenko and J. N. Goodier, Theory of Elasticity, New York: McGRAW-HILL, 1951.

[8] H. Tresca, "Mémoire sur l'écoulement des corps solides soumis à de fortes pressions," in C. R. Acad. Sci., vol 59, 754, 1864.

[9] P. A. Tipler and G. Mosca, Physics for Scientists and Egineers: Volume 1, New York: Worth Publishers, 2008.

[10] R. C. Hibbeler, Mechanics of Materials, Singapore: PERSON HALL, 2011.

[11] Calculation of the cyclic and emergency current rating of cables, Part 2: Cyclic rating of cables greater than $18 / 30$ (36) $\mathrm{kV}$ and emergency ratings for cables of all voltages, BS IEC 60853-2, 1989.

[12] "Typical Engineering Properties of High Density Polythylene," INEOS Olefins \& Polymers USA, 2009. [Online]. Available: http://www.ineos.com/Global/Olefins\%20and\%20Polymers\%20USA/Pr oducts/Technical\%20information/Typical\%20Engineering\%20Propertie s\%20of\%20HDPE.pdf [Accessed 2014].

[13] "Some Useful Numbers on the Engineering Properties of Materials (Geologic and Otherwise)," GEOL 615, Stanford Univerisity. [Online]. Available:

https://www.stanford.edu/ tyzhu/Documents/Some $\% 20$ Useful $\% 20$ Num Numb.pdf [Accessed 2014]

[14] T. Worzyk, Submarine Power Cables: Design, Installation, Repair, Environmental Aspects, Springer, 2009.

[15] “Properties of Soilds," Isidoro Martinez, 1995-2013 [Online]. Available: http://webserver.dmt.upm.es/ isidoro/dat1/eSol.pdf [Accessed 2014].

[16] J. H. Neher, "The transient temperature rise of buried power cable systems," in IEEE Transactions on Power Apparatus and Systems, vol. PAS-83, pp. 102-111, 1964.

[17] D. J. Swaffield, P. L. Lewin and S. J. Sutton, "Methods for rating directly buried high voltage cable circuits," in IET Generation, Transmission and Distribution, vol. 2(3), pp. 393-401, 2008.

[18] P. Mole, J. Featherstone and S. Winter, "Cable protection: solution through new installation and burial approaches," in SubOptic'97, San Francisco, 1997. 